\title{
OS FUNDAMENTOS DA CLÍNICA PSICOLÓGICA NA FILOSOFIA DE SOREN KIERKEGAARD
}

Ana Maria Lopez Calvo de Feijoo

Resumo: Muito se questiona acerca das contribuições que a filosofia pode trazer à psicologia, principalmente, quando essas contribuições têm origem em um filósofo que sempre assumiu ser cristão. Esses questionamentos podem ser discutidos, utilizando-se apenas as reflexões do próprio filósofo da existência, no entanto, a resposta pode se tornar mais eficiente quando a filosofia é evidenciada na prática clínica. Esse trabalho tem como objetivo apresentar os fundamentos da filosofia da existência na clínica psicológica, bem como demonstrar como isto ocorre através da apresentação de um caso clínico.

Palavras-chave: Filosofia da Existência, Comunicação Indireta, Adição, Metamorfose.

\section{A Proposta da Filosofia da Existência}

Em meados do século XIX, Kierkegaard preocupou-se com os rumos que o pensamento moderno estava tomando, alertava para o fato de que o homem estava perdendo sua singularidade, deixando-se conduzir pelo geral. Alertava para o grande perigo da publicidade, pela sua estratégia sedutora, capaz de conduzir o homem a escolhas ditadas pelo todo mundo. O perigo consistia em que o homem acabasse por esquecer de si mesmo e sem saber sequer o seu nome, acabasse permitindo se levar pelo mundo.

Inquietava o filósofo o destino do homem em um mundo onde predominavam as chamadas estéticas, com seus critérios de que tudo vale pela obtenção do prazer, com o domínio das sensações e que estas devem ser prolongadas infinitamente, mesmo que para tanto as relações aconteçam ao modo da indiferença e manipulação do outro. E, ainda, a crença consistia em que a doença constituía-se pelo domínio dos impulsos e a saúde estaria na satisfação dos mesmos.

A estratégia utilizada pelo filósofo da existência para tentar ajudar o homem foi a escrita, por isto foi autor de inúmeras obras. Sem nunca esquecer o seu projeto, traçou uma meta que estava presente da primeira até a última publicação. Queria que o leitor entrasse em contato com a sua literatura e se desse conta do lugar onde ele se encontrava; para tanto deu início a sua estratégia de duas formas: a primeira consistia em escrever sob a autoria de um pseudônimo ${ }^{1}$, pois assim se apresentava ao leitor sem que este soubesse que era Kierkegaard quem escrevera, pois se soubesse de quem se tratava a sua estratégia estaria arruinada. Precisava mostrar-se de modo a agradar o outro, assim, ganhando o seu interesse, poderia então avançar em seu plano. A segunda

${ }_{1}$ Como a utilização de pseudônimos consistia em uma sedução, Kierkegaard denomina as obras escritas por pseudônimos de estéticas. 
consistia em contar aquilo que o outro tivesse mais interesse em ouvir, ou seja, o conteúdo de sua escrita continha histórias que agradavam aqueles que atuavam de modo estético, predominantemente; continha sistematizações que atraiam os éticos. E, assim, tentava desembaraçá-los dos laços da ilusão.

\section{A Utilização dos Pseudônimos}

Kierkegaard era bastante conhecido na Dinamarca como aquele que a todo o momento criticava a ordem vigente e as instituições. Possuía uma capacidade de ironizar os líderes religiosos e políticos que acabava por provocar a ira daqueles que exerciam o poder. Com isto acumulou muitos inimigos, sempre prontos a desvalorizar sua pessoa bem como suas apresentações. Kierkegaard passa a publicar suas obras através de pseudônimos. A fim de organizar a sua estratégia de comunicação, classifica a existência humana em estética, ética e religiosa, de acordo com os referenciais pelos quais o homem estabelece suas escolhas.

Descreve o modo estético de existir como aquele que prioriza o prazer, a diversidade, o descompromisso com o outro. Desconsidera toda e qualquer conseqüência e lida de forma indiferente com os resultados de sua ação. Auto-centrado, perde-se em si mesmo ou nas solicitações diversificadas do mundo, nas ofertas disponíveis. Ilude-se pensando que pode construir uma existência onde só há lugar para o prazer. Enquanto que no modo ético de existir prioriza-se o justo, o certo, o bom. Reconhece-se os conseqüentes e assume-se a responsabilidade por eles, por isto leva uma existência preocupada. Corre o risco de perder-se de si mesmo nas solicitações impostas pelas regras. Ilude-se, pensando que pode construir uma existência perfeita, sem erros e imperfeições; no modo religioso de existir, o homem prioriza a humildade e a entrega a desígnios sobre os quais não se tem controle dos conseqüentes. Aceita a realidade e enxerga a si mesmo como vivendo sob o paradoxo entre aquilo em que pode interferir e legislar e aquilo que transcende ou que se coloca fora de suas limitações e que se constituem em seus necessários. Ilude-se ao pensar a si mesmo como tendo alcançado um estado definitivo em que não se sente mais solicitado pelo mundo.

Para alcançar o homem que privilegia o modo estético de existir, escreve obras com conteúdo estético, e assim tenta despertar o interesse do leitor para a condição humana, a sordidez e o vazio da existência humana ordinária. Da mesma forma, atua com aquele que predominantemente utiliza referenciais éticos, escrevendo, por exemplo, na figura de um juiz como manter o caráter estético no matrimônio ético. E ao religioso, endereça um conteúdo de fé, como por exemplo, a passagem bíblica de Abraão e Isaac.

\section{Considerações acerca do "ajudante"}

Kierkegaard denomina "ajudante” àquele que pretende ajudar ao outro a se desembaraçar dos laços da ilusão, a não deixar que o homem se perca no impessoal, 
esquecendo-se do caminho de volta a si mesmo. Diz que aquele que quer ajudar deve, antes de tudo, reconhecer que tem um diferencial em relação ao outro. Deve estar na adição, isto é, reconhecer-se no seu projeto, naquilo que lhe é mais fundamental, e não se perder no plural, nas demandas do mundo. Só assim pode tentar identificar a ilusão do outro, introduzindo o elemento dialético; finge compartilhar da ilusão de forma a provocar no outro a reflexão. Aquele que quer ajudar, deve estar atento para não se deixar seduzir pela ilusão do outro, e isto só é possível porque há a adição, que no final das contas, consiste em um diferencial entre os dois: ajudante e ajudado.

Aquele que ajuda deve saber dialogar através da comunicação indireta, que consiste em uma forma de se fazer chegar ao outro sem que este perceba que há aí uma intenção de confrontá-lo, de questioná-lo ou interceptá-lo em suas ações. Dentre os modos de comunicação indireta, o filósofo recomenda a ironia, que consistia em um método de comunicação indireta, utilizado por Kierkegaard para que naquele que predomina o modo estético de escolher surja primeiramente a inquietação, o impacto, de forma a que este homem, pelo menos, possa reconhecer-se no lugar em que se encontra. E assim abrir a possibilidade de se instaurar o conflito, a indecisão.

\section{Estudo de Caso}

Em 24 de julho de 1848, Kierkegaard escreve um artigo para um jornal dinamarquês, refletindo sobre a vida de uma atriz que inicia no palco aos 16 anos, dedica-se durante 14 anos ao teatro e aos 30, quando convidada a representar o papel de Julieta de Shakespeare, recebe severas críticas do público ético, que valoriza a juventude no sentido temporal em detrimento ao essencial da genialidade. Ressalta a importância da avaliação estética, na qual permanece a valorização da genialidade da atriz, que traz à tona as sensações do espectador esteta.

Com base neste texto de Kierkegaard, discutiremos uma situação clínica em que uma atriz renomada busca acompanhamento psicológico por encontrar-se numa crise com relação a sua vida profissional.

Kierkegaard (2007, p.4) inicia o seu relato da seguinte forma:

Eu acredito que, a maioria das pessoas, ao pensarem em uma atriz renomada, imaginam que sua condição de vida seja encantadora e brilhante e geralmente se esquecem de seu lado espinhoso: as muitas inacreditáveis trivialidades e toda a sorte de injustiça e incompreensão justamente no momento crítico e a atriz não lhe cabe alternativa a não ser resignar-se.

É justamente esta situação que será retratada neste estudo de caso. Flávia ${ }^{2}$, uma mulher de 32 anos, procura a psicoterapia com a seguinte questão: "Estou entediada com a vida, não estou mais suportando conviver com as pessoas, as pressões que o mundo vem me expondo são insuportáveis. Nunca na minha vida de atriz fui tão exposta a críticas".

${ }^{2}$ Nome fictício. 
Ao tematizar o tédio, retomo o que Kierkegaard (2006) no texto intitulado " $A$ rotação dos cultivos: ensaio para uma doutrina de prudência social" afirma ser o tédio. Diz que se trata da raiz de todos os vícios e de todo mal, por isso, recomenda mantê-lo à distância e procurar vencê-lo. Porém, como? Através de uma ilimitada infinitude de mudanças, em uma dimensão extensiva, respeitando o princípio da limitação, o qual julga ser aquele que salva em um mundo repleto de solicitações. Exemplifica a situação com a rotação dos cultivos tal como acontece com os camponeses, que não transformam o terreno, trocam o método de exploração e a classe de sementes. Diferentemente, daquele que está entediado de viver no campo e viaja para a capital, farto da sua terra natal e viaja para o estrangeiro. Ao viver uma determinada situação cai no tédio e o resolve mudando a situação externa, sem reflexão abomina a repetição e parte sempre em busca da novidade. Busca esta que ao não considerar o princípio da limitação jamais se esgota.

Flávia dizia: "sofro de tédio". Parecia desconhecer a ilimitada infinitude de mudanças considerando o princípio da limitação. Ao mesmo tempo, revelava a crise estética a que Kierkegaard se referia ao falar da crise na vida de uma atriz.

Flávia era uma atriz com bastante repercussão na mídia, havia participado de muitos filmes e novelas no papel de protagonista. Jovem, bonita, sensual, apresentava-se com extremo esplendor, provocava suspiros, inveja e admiração. Muito aplaudida e requisitada pela sociedade e pela mídia, até então. Porém, agora, aos 32 anos, as coisas começavam a mudar. A própria mídia que outrora lhe dera o estrelato, agora a criticava pelo seu envelhecimento, dizendo que aquele lugar não lhe cabia mais, estava um tanto quanto inadequada, já era a hora de substituí-la por uma mulher com os mesmos atributos, porém mais jovem. Flávia não convencia mais no papel jovial, uma vez que a juventude não era mais um atributo que lhe pertencia. Esta mesma situação é ilustrada por Kierkegaard ao referir-se a crise da atriz de seu tempo: a mesma intensa publicidade que nunca parou de ecoar na grande bateria da trivialidade, em prol de seu orgulho e a honrou com adoração, esse mesmo público tornou-se agora entediado com o artista idolatrado (Kierkegaard, 2007, p. 5).

Nisto consistia o sofrimento psíquico de Flávia, vivia o trágico, e, portanto, o inevitável, seu destino da passagem do tempo que, culturalmente, leva ao descarte. Para Maffesoli (2003) uma das principais características do retorno do trágico nas sociedades pós-modernas ocorre na vivência da temporalidade - a juventude que se acaba, ao mesmo tempo em que é extremamente valorizada, daí o grande mito da pós-modernidade passar a ser a síndrome de Peter Pan, ou seja, da "criança eterna”.

Romilly (1995) ao analisar a origem da preocupação com o tempo observa que a palavra kronos aparece nos autores trágicos: Ésquilo, Sófocles e Eurípedes. Acredita que com estes surge a preocupação com a condição trágica do tempo, acompanhada de angústia e desespero. Nisto consistia o sofrimento de Flávia: o tempo, a perda da vinha o pedido de socorro: "Agora, a situação se agravou dentro de mim. A próxima 
novela será dirigida por um Diretor que gosta muito de meu trabalho e quer que o papel seja meu. Porém, o escritor não concorda, diz que a protagonista por ele idealizada é mais jovem e que eu, no papel, não convenceria. Esse conflito entre os dois vem me mobilizando muito. No fundo, penso que os dois estão de acordo, o Diretor quer apenas que eu tenha uma oportunidade para me despedir. Mas, na verdade os dois temem não agradar o público. Na verdade, os dois não me querem mais".

Uma análise baseada no escrito de Kierkegaard seria de que o Diretor acredita que:

(...) a trivialidade vulgar está fluindo tão energeticamente da admiração anterior, que mesmo o ídolo tendo envelhecido, ainda pode usufruir deste momento por algum tempo. Nenhuma mudança obvia é observada nas manifestações do público em relação ao artista idolatrado; parece ainda detectar uma certa hesitação, que vai contra o fato de que o adorado. (Kierkegaard, 2007, p.6).

Já para o autor da novela:

O público quer se livrar dela, tirá-la de seu campo visual; e a atriz pode agradecer a Deus que este mesmo público não a quer morta. Esse mesmo público tem um novo ídolo de dezesseis anos e em honra a nova atriz, o ex-ídolo deve sentir o repúdio total do público - pois esta é a grande privação que está envolvida no fato de ser um ídolo. É impensável acreditar que alguém possa se resignar com esta posição com honra. E resignar-se é tão ruim quanto se indignar (Kierkegaard, 2007, p.5).

Kierkegaard, em seu texto, refere-se ao crítico Rosiflengus, que prefere continuar elogiando, sendo cortês: "Mas, ser cortês em relação a um artista, representa, precisamente, o mais alto grau de insolência, uma impertinência insana e um intrometimento tenebroso". Dizia Flávia: “Não sei o que é pior se saber que me oferecem o papel só para me agradar ou se acabar de vez com esta situação terminal. O que me faz mal na verdade é saber que me dediquei tanto, que representar foi o mais importante na minha vida e agora esta situação".

Questiona Kierkegaard :

Mas agora, qual a razão dessa desumanidade que dirige tanta injustiça e até mesmo crueldade contra mulheres dedicadas ao serviço da arte? Qual a razão, exceto por aquele cultivo estético que é tão raro entre as pessoas? Aonde o feminino é considerado, a apreciação da arte para a maioria das pessoas está em suas categorias essências e em seu modo de pensar, como o mesmo que em cada aprendiz de açougueiro, oficial da guarda ou vendedor que fala com entusiasmo sobre uma beleza condenada ou sobre um diabo com uma bela vivacidade de dezoito anos. Esses dezoito anos, essa beleza condenável e essa vivacidade diabólica, que é a apreciação da arte - é também sua brutalidade (2007, p.6). 
Flávia não via outra saída a não ser a terminalidade, comungava com a visão do público e da crítica. Onde estava aquela vivacidade que se encontrava até então em Flávia? Kierkegaard refere-se à metamorfose, já que perguntava onde estava aquele furor de outrora, furor que segundo ele nunca se esgota. E que era exatamente este furor que levaria à metamorfose. Com a ajuda da psicologia, refletindo sobre a questão, poder-se-ia antecipar a metamorfose, estas idéias ficam claras nos seguintes trechos:

(...) quando a interioridade caminha em direção a si mesma, é revelada com intensidade na metamorfose: então a opinião da massa perde o interesse (Kierkegaard, 2007, p.6).

Por outro lado, também é verdade que quando a metamorfose é bem sucedida, não interessa nenhuma conversa cortês, pois somente então há admiração. (...) É claro, muito é feito para a atriz, no teatro, garantir seu futuro. Eu acredito que também seria muito lucrativo se, em absoluto, essa superstição antiestética sobre os dezoito anos, pudesse acabar e ser esclarecido que o momento mais decisivo ocorre depois - isso também promoveria uma segurança para o futuro da atriz. O próprio assunto não tem um interesse somente estético, mas também psicológico. Estou surpreso que isso não se tornou, com mais freqüência, um assunto para a reflexão. O interessante é ser capaz de, de uma forma puramente estética, porém com a ajuda da psicologia, antecipar a metamorfose ou pelo menos, explicá-la, quando ela se instaurar (Kierkegaard, 2007, p.7).

Kierkegaard pede aos espectadores antiestéticos que fiquem em silêncio, para assim não arruinarem a metamorfose, pois o público, com seus caprichos, fica com raiva porque "o tempo tomou a liberdade de tornar os favoritos dez anos mais velhos".

Eu devo meramente, fazer uma tentativa aqui, de uma maneira puramente psicológica e estética, descrever uma metamorfose, certamente uma que seja difícil, e também por essa razão, uma que também seja bonita e significativa. Por mais que tenha se dedicado e por mais que tenha se comprometido à primeira fase, mais difícil é para desenvolver uma nova fase. E que os espectadores essencialmente antiestéticos possam como compensação, serem afortunados o bastante pra conseguir sua metamorfose em todo seu silêncio (Kierkegaard, 2007, p.7).

Com o pensamento clínico iluminado pelo texto de Kierkegaard, fazia-se necessário buscar o furor, a vivacidade, a juventude de outrora que pareciam agora estar apagados, diz Kierkegaard: 
(...) é esteticamente apropriado que eu discurse sobre tal começo jovial por outra razão também; uma vez que o sujeito dessa investigação é a própria metamorfose, eu não estou preocupado nesse artigo com sua fase jovial como tal. A representação dessa primeira fase tem o intuito de apresentar os alicerces, sendo poeticamente e filosoficamente uma lembrança, porém sem tristezas (Kierkegaard, 2007, p.8).

Buscou-se a história do início da carreira de Flávia, queria encontrar os alicerces, que ela ainda possuía, e então compreender o que Flávia estaria fazendo com aquilo que possuía: "Tive sempre muita sorte, comecei nas aulas de teatro e logo fui chamada para fazer novela. Logo na primeira apresentação fiz muito sucesso, o público desejava que eu aparecesse, meu papel foi crescendo, aquilo me alimentava, me inspirava. Parecia um círculo vicioso, quanto mais o público gostava, mais eu me animava. Fazia com gosto, decorava o texto, lhe dava vida, assumia o personagem. Tornou-se minha vida. Muitas outras novelas, peças, cinema. Admirada por todos, a crítica toda favorável".

Sobre toda essa vivacidade, Kierkegaard comenta:

É surpreendente. Em outros casos, você pode apenas especificar, exatamente, a qualidade que a pessoa possui e quando você tiver terminado, você pode ver exatamente o quanto essa pessoa está fazendo com - o que ele possui. Por outro lado, uma jovem atriz que possui essa qualidade indefinível faz, imediatamente, com que quaisquer outros proprietários pareçam pobres por comparação (Kierkegaard, 2007, p.8).

Flávia chamava todo o seu sucesso e a sua vivacidade e habilidade em representar de sorte, Kierkegaard diz sobre isto:

Mas, para chegar um pouco mais perto para que se possa definir essa posse indefinível, vamos chamá-la de sorte. Ela está em posse da sorte. Sorte não significa aqui que ela é afortunada o suficiente para se engajar no teatro em termos rentáveis, ou afortunada em ter o diretor e as criticas interessados nela. Não, sorte significa aqui o que César quis dizer quando ele disse ao capitão do navio: você esta carregando César e sua sorte (Kierkegaard, 2007, p.9).

Era preciso que o psicoterapeuta na adição, reconhecendo-se no seu projeto, naquilo que lhe é mais fundamental, e não se perdendo no plural (demandas do mundo), pudesse identificar a ilusão do outro, finge compartilhar dessa ilusão, de forma a poder introduzir o elemento dialético, provocando assim no outro a reflexão. Aquele que quer ajudar deve estar atento para não se deixar seduzir pela ilusão do outro, e isto só é possível porque há a adição, um diferencial entre os dois; poder então ajudar Flávia a reconhecer que seu talento lhe pertencia e que ela simplesmente o chamava de sorte. 
Para tanto, o psicoterapeuta continuava a perguntar sobra a sua sorte: "Em que outras situações de sua vida a sorte te acompanha" ?

Flávia, prontamente discursava sobra a sua sorte: "Desde sempre, sempre tive amigos, as pessoas sempre ficavam por perto, era convidada para participar das atividades, festas, reuniões. Em gincanas sempre ganhava prêmios, conseguia bons namorados. Hoje tenho autonomia financeira, minha família está bem. Não tenho do que me queixar, a sorte sempre me acompanhou".

O psicoterapeuta tenta mobilizá-la e diz: "Parece que só agora a sorte te abandona".

Flávia fica em silêncio por alguns segundos e responde: "Não, não foi a sorte que me abandonou, eu envelheci. Por isso as mesmas oportunidades não me são dadas. Se fosse ainda jovem continuaria atuante".

O psicoterapeuta continua tematizando a sorte: "Então, agora não é falta de sorte e sim de juventude".

Flávia consente e diz: "Sem juventude você não tem nenhuma chance, pelo menos na vida de atriz".

Psicoterapeuta: "Você disse nenhuma chance, como assim?"

Flávia: "É, de sucesso".

Psicoterapeuta: "E para você só vale o sucesso, não é assim?”.

Flávia: "É, preciso de sucesso, respiro o sucesso. E não apenas o sucesso, mas o maior de todos".

Psicoterapeuta: "E se não for assim, então o melhor é desaparecer".

Flávia: "Foi isso que eu disse. Fico pensando não pode ser de outro jeito?"

Psicoterapeuta: "Pode ser de outro jeito?".

Flávia: "Claro que pode. Eu perdi a juventude, não tenho mais a beleza da juventude para oferecer ao público, mas tenho talento. Esse nem o tempo, nem o público pode me tomar".

Flávia já reconhecia o seu talento, que outrora chamara de sorte. Agora ficava indecisa, questionava se deveria abandonar o palco e assim permaneceria na memória do público como a bela e jovem atriz ou se continuava no palco, porém, sem mais ser reconhecida com a beleza da juventude. Flávia desconhecia a ilimitada infinitude de mudanças em sua dimensão extensiva, bem como desconhecia o princípio da limitação; queria a juventude do temporal , seus 17 anos para sempre. Kierkegaard com relação a sua atriz, diz:

Ela (a sorte) a atende aonde quer que ela vá e aonde quer que ela pare, em tudo que ela se compromete, no mínimo movimento de sua mão, em cada piscada de seu olho ou balanço de sua cabeça, em todo movimento de seu corpo, em seu gesto, em sua voz, em sua expressão facial. Resumindo, a sorte a corteja a tal nível que a crítica sensível não é capaz de detectar, nem por um segundo, o que ela seria, afastada de sua sorte, mesmo que ela já esteja esteticamente consciente de que os melhores aspectos de seu talento, em outro sentido, pertencem a ela (Kierkegaard, 2007, p.9). 
A crítica refere-se à falta de juventude, e é o que Flávia alega como motivo para abandonar a sua carreira. Acerca desta justificativa afirma Kierkegaard:

Isso revela que sua liberdade é inexoravelmente rica, que indica o quanto mais ela possui. Revela que sua sedução (e uma personalidade absolutamente sem sedução é impensável) não é nada mais do que uma mente feliz, inocente e exuberante, consciência triunfante de sua indescritível sorte. Não é, portanto realmente sedução, mas algo que encoraja o espectador a ir além; ou seja, assegurando a ele a confiabilidade de toda performance, fazendo com que ele esteja completamente certo que sua exuberância é segura (Kierkegaard, 2007, p.10).

Para Kierkegaard, a sorte constitui-se no talento da atriz, assim como a juventude refere-se à vivacidade, ao vigor, à confiabilidade e à exuberância. Flávia já tomara consciência de seu talento, o qual outrora chamara de sorte. A dúvida agora consistia em se apresentar com sua idade ou deixar que permanecesse no imaginário dos telespectadores com a juventude de antes. Flávia precisava decidir, ela mesma vivia esse dilema. Nas palavras de Kierkegaard (2006); “decidir não é um mero isto ou aquilo, toda decisão implica em conseqüências, não só para si mesmo como para outrem" (p.25). Para este filósofo, quando a pessoa se encontra em uma encruzilhada tal como Flávia, a decisão amadurece a alma.

Flávia não mais tomava atitudes sem se comprometer com suas palavras, refletia, por isso agora proferia "ou" isto, "ou” aquilo. Acerca disto, afirma Kierkegaard (2006): "Há pessoas cuja alma é demasiado dissoluta para compreender o que significa tal dilema e cuja personalidade está privada de energia necessária para dizer com paixão: ou ... ou” (p.16). Flávia agora reconhecia a dúvida, a indecisão, as conseqüências.

Por outro lado, Kierkegaard alerta que aquele que acompanha a decisão do indeciso, também se compromete com as palavras que utiliza na tentativa de ajudar o indeciso a decidir. $\mathrm{O}$ ajudante deve cuidar do que fala, sem esquecer da seriedade, e cuidar também para não atuar com uma seriedade dissimulada.

Agora, frente à indecisão de Flávia, o psicoterapeuta arrisca: "Você não sabe se permanece jovem para sempre na memória do público ou se permite que sua juventude desapareça dessa mesma memória. Como a exemplo de nosso ídolo do futebol, Pelé, que se manteve jovem para sempre na memória do público ou como Fernanda Montenegro que ainda é premiada como uma grande atriz, porém a vista do público é velha. Por outro lado, há pessoas famosas que como não bateram em retirada ao envelhecerem e o público tece criticas acerca de suas permanências. Qualquer que seja a sua decisão, você corre riscos".

Flávia: "É, é isto que me atormenta, não sei qual o risco que eu quero correr".

A atriz descrita por Kierkegaard tinha a posse indefinida de talento, vivacidade e genialidade, por isso não tinha o que temer. Precisava, no entanto, tomar consciência de sua posse indefinida. Precisava assumir para si e só para si 
mesma a sua vocação, desta forma, nem o público, nem a mídia, a assustariam mais; o seu trabalho consistiria em algo original em sua paixão imediata, onde pensamento e idéia fossem relevantes, estivessem em ressonância, "que ela seja uma sensibilidade específica e original”. Nas palavras de Kierkegaard (2007):

Dessa forma, ela se relaciona expressivamente às palavras do escritor; mas para ela, relaciona-se ainda além, ao que poderia ser chamado de tom articulado a cada fala e a harmonia modulada ao personagem por inteiro. Ela não apenas tira as palavras da boca do escritor corretamente, mas ela as devolve a ele de tal maneira, acompanhando o som de sua vivacidade e de sua consciência e genialidade, que até parece dizer: deixe-me ver se você pode copiar isto (p.12).

Porém, ultimamente, Flávia referia-se à grande ansiedade que a dominava antes de entrar no palco: "Entrar no palco, me deixa inquieta, perturbada. Crio muitos medos, de não memorizar o texto ou então esquecer. Com isto perco muito tempo na memorização, fico muito insegura. Fico tensa antes da apresentação, depois, não, esqueço e me entrego plenamente ao papel".

Lembro, então, do que diz Kierkegaard (2007) ao referir-se a sua atriz:

Sua posse indefinida finalmente significa: que ela está na correta afinidade com a tensão do palco. Cada tensão, de acordo com o próprio argumento da dialética, pode ter dois efeitos distintos. Pode revelar a ansiedade que a tensão cria, mas também pode ser o oposto, podendo escondê-la e não apenas escondê-la, mas constantemente transformá-la, mudá-la ou transfigurá-la em leveza. Portanto, a leveza é invisivelmente aprisionada à ansiedade produzida pela tensão, porém essa ansiedade não é nem vista e nem suspeitada; somente a leveza é revelada (p.12).

E questiono: “Essa tensão vem ocorrendo desde quando?”.

Flávia: "Acho que começou daí, venho sofrendo com as críticas, não sou mais admirada pelo público. Fico com medo de errar e as coisas piorarem".

Psicoterapeuta: "Antes disto você não ficava ansiosa".

Flávia: "Não, é claro que uma certa dose de expectativa sempre acontece. Muitos atores confessam esse frio na barriga antes de entrar no palco ou nos primeiros momentos. Mas isto não me incomodava, lidava bem com essa ansiedade. Agora não, meio que me paralisa".

Psicoterapeuta: "O que será que incomoda agora?".

Flávia: "Agora tenho medo. O medo me domina. Medo do público, medo da crítica. Agora tudo se resume a medo".

Psicoterapeuta: "Antes não havia medo, por isso a sensação de paralisação inexistia".

Flávia: "Medo, tédio, tristeza, desânimo, isto tudo é que me faz quere desistir". Psicoterapeuta: "Desistir é uma boa forma de acabar com o medo". 
Flávia: "Mas é justamente querer desistir que torna a minha vida sem sentido, eu queria poder continuar sem medo. O que eu não sei é como vencer o medo".

Psicoterapeuta: "Esta é a questão: o que fazer para acabar com o medo?”.

Flávia queria acertar na sua escolha e esforçava-se, seriamente, para tanto. Queria tornar-se transparente para si mesma, conhecer seus propósitos, suas mentiras, seus inexplicáveis disfarces. Acerca disto diz Kierkegaard:

A transparência de si mesmo é algo natural no homem, no entanto quando ele atua de acordo com as circunstâncias da vida, a transparência pode então se tornar impossível, a ponto de não mais se manifestar, e então este homem fica impossibilitado até mesmo de amar (2006, p.20).

E decidi seriamente levar Flávia a refletir sobre seus diferentes disfarces e o quanto estes tinham lhe roubado o seu poder de decisão: "Primeiro você diz que foi bem sucedida pela sorte, depois alega falta de juventude, depois diz que quer se tornar eternamente jovem, ou seja, inventa inúmeras desculpas para parar de atuar. Do que realmente você está fugindo?".

Flávia: "Da crítica, dos outros, de deixar de ser a melhor de todas. Com a beleza e a juventude isto era fácil. Mas sem beleza e juventude sei que é difícil. Inclusive já fico muito ansiosa ao me apresentar. Sinto-me insegura com a avaliação do público. Acho que não agrado mais. Quando penso nisso é que tenho vontade de desaparecer, mas quando penso no que fazer, não vejo mais nada, paraliso. Fico entediada. Vejo no que a minha vida se transformou. Lembro da minha mãe, mãezona, aquela que se dedicava inteiramente aos filhos e quando todos tomaram seus rumos, ela mesma dizia que ávida tinha perdido o sentido. Ela não tinha mais o que fazer, não tinha mais de quem cuidar. Foi só meu pai morrer, que ela caiu em depressão, nem remédio, nem médico, nada adiantou. Agora entendo ela muito bem. Sinto a mesma coisa. A vida perde o sentido, aí o desanimo, uma vida sem amanhã, um dia atrás do outro, todos iguais".

Psicoterapeuta: "A tua vida profissional só tem sentido se você for a melhor de todas, se assim não for, você desiste e vive, como você falou no início, uma vida entediante. Você prefere o tédio a deixar de ser a melhor de todas. Apenas a melhor de todas faz sentido em sua vida".

Flávia: "É triste esta escolha. Como posso ser tão vaidosa? Como alguém pode escolher abandonar tudo que construiu durante toda uma vida?".

Psicoterapeuta: "Mas é o que você escolhe".

Kierkegaard (2007, p.15) afirma que "de todos os sofistas, o tempo é o mais perigoso de todos os perigos e o hábito o mais astuto".

Flávia havia se habituado a ser admirada, a ser a primeira. Garantia-se na sua beleza e na sua juventude, por isso nunca se dera conta de suas posses indefinidas. Havia se tornada uma atriz muito popular e com muitas aparições em público. Gostava disto, sentia-se vaidosa e prestigiada com tantos convites. Ficara tão ocupada com as solicitações e elogios que esquecera do princípio da limitação. E até o público havia se convencido que sua beleza e juventude consistiam no seu valor. 
Era preciso continuar a buscar suas posses indefinidas. Kierkegaard referese às posses indefinidas de sua atriz. Posses estas pelas quais pode ocorrer a metamorfose, ou seja, a passagem da valorização do acaso e do transitório para a verdadeira cultivação estética da genialidade e da relação com a idéia, já que estas são eternas e essenciais:

Essa atriz era constituída de juventude feminina, apesar de não o ser pelo sentido usual do termo. O que normalmenteé chamado de juventude se desgasta com os anos, pois o tempo pode se perder amorosamente e cuidadosamente, mas também captura tudo o que é finito da mesma forma. Mas, na atriz, há uma genialidade especial que corresponde a cada idéia: a juventude feminina. Isso é uma idéia e a idéia é algo bem diferente do fenômeno de se ter dezessete anos. Uma menina pode estar desprovida de qualquer idéia e ainda ter dezessete anos. Sem a correlação da genialidade com a idéia, não poderia haver discurso sobre a metamorfose. Mas justamente ser esse o ponto, e a idéia ser o que é, sem comprometimento, a metamorfose é excepcional. (Kierkegaard, 2007, p.19).

Em posse destas reflexões, lembrei-me da atriz em algumas de suas atuações que tive a oportunidade de assistir, dava-me conta de sua genialidade, da vitalidade, do poder de sedução pelo vigor de sua representação, desde muito jovem, mesmo em papéis de mocinha, de namoradinha. Lembro-me novamente de Kierkegaard (2007), quando afirma: (...) "a metamorfose deve estar presente desde o início, mas somente depois que algum tempo já se passou, é que ela pode ser trazida à tona ou se manifestado por inteiro. Essa manifestação é precisamente a metamorfose” (p.20).

Com certeza, não era a juventude, nem a beleza de Flávia que deixavam o público perplexo, mas a sua tensão contagiante quando estava no palco; este se fundia com a platéia. Diz Kierkegaard (2007):

Uma mulher que possui a juventude feminina, somente no senso comum, não pode receber a metamorfose, uma vez que a juventude, neste sentido, não é dialética por si mesma. Tem apenas uma única vida, que é consumida pela entrada da dialética ao invés de ser separada ou deixada de lado. O tempo é a dialética que vem da ausência, que consome essa juventude antidialética mais cedo ou mais tarde (p.20).

Flávia precisava poder reconhecer o seu desespero do eterno, reconhecer a sua temporalidade e o que nela permaneceria eterno. Afetava-se pelos ditos do público, esquecendo-se de sua genialidade. Cabia então ao psicoterapeuta despertála para si mesmo, de modo a que Flávia não se perdesse no falatório do impessoal:

Para tanto, o psicoterapeuta insistia: "Sem beleza e sem juventude acabou toda a capacidade de representar que parecia existir em você?" 
Flávia: "De representar não, de agradar sim".

Psicoterapeuta: "Então para você o sentido de tua vida é muito mais agradar do que representar. E você acredita que o que agrada é a juventude, como esta se esvai, não há como continuar sua vida de atriz"?

Flávia: "Parece meio ridículo como posso me aniquilar só porque não sou tão jovem?".

Psicoterapeuta: "Parece que você só presta atenção ao que perdeu, mas não dá a mínima para o que ganhou".

Kierkegaard (2007) com relação à atriz de seu tempo, defendia:

O tempo tem firmado seu direito; ele tirou algo do imediato dela, sua primeira, direta e fortuita juventude. Mas também, pelo fazer do tempo, simplesmente faz de sua genialidade o manifesto mais essencial. Ela perdeu aos olhos da platéia, ela ganhou em sentido ideal. O tempo das confusões da galeria é passado, se ela for interpretar Julieta, não poderá haver nenhuma menção em criar um furor como senhoria Julieta. Se ela for interpretar Julieta, deve ser uma apresentação eminente ou mais corretamente uma apresentação no sentido eminente (p.22).

Flávia: "E o que ganhei?".

Psicoterapeuta: "O que você ganhou?".

Flávia: "Experiência".

E isso é simplesmente a metamorfose. Possibilidade contra possibilidade, é dito também aqui: dialética contra dialética, pois o tempo não tem poder algum de destruir mas somente um poder subserviente, que serve para tornar manifesto (Kierkegaard, 2007, p.20).

Conclui Kierkegaard (2007) no seu artigo do jornal:

Espero que esse artigo tenha sido bem sucedido em mostrar o quão seguro a essência do futuro da atriz realmente é, apesar dos anos. Se atingir esse objetivo, será uma grata satisfação para mim, ainda mais porque, estou convencido que ao invés da concepção certa do futuro da atriz, há numerosos contra-sensos. Pelo mesmo contra-senso que desconstrói e anti esteticamente supervaloriza o começo, também desconstrói e anti esteticamente distorce o que está por vir, que é, o mais sublime de tudo (p.25). 


\title{
Referências Bibliográficas
}

Kierkegaard, S. (2006).O lo uno o lo outro: un fragmento de vida. Madrid: Editorial Trotta (Originalmente publicado em 1843).

Kierkegaard, S.A. (2007). A crise e uma crise na vida de uma atriz. Cadernos IFEN de Tradução. Rio de Janeiro: Editora IFEN.

Maffesoli, M. (2003). O instante eterno: o retorno do trágico nas sociedades pósmodernas. São Paulo: Zouc.

Romilly, J. (1995). Le temps dans la tragédie grecque . Paris: J. Vrin.

\begin{abstract}
A lot is questioned about the contributions that the philosophy can bring to the psychology, mainly when these contributions has its origins in a philosopher who has always assumed to be Christian. These questionings can be discussed by taking into consideration just the reflections from the existence philosopher himself. However, the answer can be more efficient when the philosophy is shown in the clinical practice. This essay has the objective of presenting the fundamentals of the philosophy of existence as well as show how this occurs by presenting a clinical case.
\end{abstract}

Key-words: Existential Philosophy, Indirect Communication, Addiction, Metamorphosis.

Resumen: Mucho se cuestiona sobre las contribuciones que la filosofía puede traer para la Sicología, principalmente, cuando esas contribuciones se originan en un filósofo que siempre se mostró cristiano. Esos cuestionamientos pueden ser discutidos utilizando, sólo, las reflexiones del propio filósofo de la existencia. Sin embargo, la respuesta puede ser más eficiente cuando la filosofía es evidenciada en la práctica clínica. Este trabajo tiene como objetivo presentar los fundamentos de la filosofía de la existencia en la clínica sicológica y demostrar como eso acontece a través de la presentación de un caso clínico.

Palabras-clave: Filosofía de la Existencia, Comunicación Indirecta, Adición, Metamorfosis.

Ana Maria Lopez Calvo de Feijoo é Doutora em Psicologia pela Universidade Federal do Rio de Janeiro (UFRJ), Sócia Fundadora e Presidente do Instituto de Psicologia Fenomenológico-Existencial do Rio de Janeiro (Ifen), Responsável Técnica, Professora, Supervisora e Orientadora de monografia do Curso de Especialização em Psicologia Clínica e Professora Adjunto da Universidade do Estado do Rio de Janeiro (UERJ). Email: feijoo@ifen.com.br 